\title{
Mechanism of Therapeutic Effect of High-dose Intravenous Immunoglobulin Attenuation of Acute, Complement-dependent Immune Damage in a Guinea Pig Model
}

Milan Basta, Paul Kirshbom, Michael M. Frank, and Louis F. Fries

Laboratory of Clinical Investigation, National Institute of Allergy and Infectious Diseases, National Institutes of Health, Bethesda, Maryland 20892

\begin{abstract}
Studies were performed in in vitro and in vivo models to assess the effect of intravenous immunoglobulin (IVIG) on the development of acute complement-mediated tissue damage. IVIG significantly increased the duration of survival and frequently prevented the death of guinea pigs injected with anti-Forssman antiserum to cause lethal Forssman shock; no control animal treated with albumin and/or maltose vehicle survived. The most pronounced effect was achieve by delivering IVIG as one slow injection at $1,800 \mathrm{mg} / \mathrm{kg} 3 \mathrm{~h}$ before Forssman shock was elicited. Infusion of guinea pig IgG at the same dosage was similarly protective. A strong positive correlation was found between IgG plasma levels and survival time in guinea pigs treated with graded doses of IVIG. Therapy itself did not affect $\mathrm{C} 3$ and $\mathrm{C} 4$ levels nor the capacity to activate these components. In vitro studies showed almost complete inhibition of $\mathrm{C3}$ uptake onto IgG-sensitized erythrocytes using serum from an IVIG-treated animal. We suggest that supraphysiologic levels of IVIG act in part by preventing active C3 fragments from binding to target cells. Infusion of high dose IVIG may be a rational approach to modulating acute, complement-dependent tissue damage in a variety of diseases in man.
\end{abstract}

\section{Introduction}

Forssman or heterophile shock is a well-studied immunopathological reaction produced by intravenous infusion of rabbit anti-Forssman antiserum into guinea pigs. It is characterized by hypotension, pulmonary edema, pulmonary hemorrhage, and death occurring within minutes after injection of the antiserum. Forssman shock has been classified as a type II reaction using the system of Coombs and Gell (1). These reactions are cytotoxic and are caused by IgG or IgM antibodies to cellular antigens. Combination of the antibodies with their cognate antigens elicits complement activation and produces tissue damage through direct cytolysis, recruitment of inflammatory cells, or both.

The Forssman antigen is a lipopolysaccharide of $\sim 1,000$ mol wt that is widely distributed in the tissues of guinea pigs (and many other species), where it is primarily situated in

Address reprint requests to Dr. Basta, Laboratory of Clinical Investigation, National Institute of Allergy and Infectious Diseases, National Institutes of Health, Building 10, Room 11N228, 9000 Rockville Pike, Bethesda, MD 20892.

Received for publication 13 January 1989 and in revised form 3 August 1989.

The Journal of Clinical Investigation, Inc.

Volume 84, December 1989, 1974-1981 vascular endothelium and adventitial tissues (2). The antigen is absent from blood cells in the guinea pig, so intravenous administration of anti-Forssman antiserum results in antibody binding to endothelial cells in the first major capillary bed encountered, the pulmonary capillaries. The subsequent lethal reaction is mediated by the IgG fraction of the antiserum and is absolutely dependent upon complement activation via the classical pathway $(3,4)$. Guinea pigs genetically deficient in C4 are insusceptible to Forssman shock until repleted with exogenous $\mathrm{C4}$, whereupon reactivity is reconstituted (4). Aggregation of platelets with or without mediator release may also have a role, but this is less well defined (5). There is no histopathologic evidence for the involvement of neutrophils or other leukocytes, and profoundly neutropenic animals succumb readily to the same dose of antiserum as normals (6).

In this study, marked prolongation of survival time and/or protection against death was achieved when guinea pigs were treated with high doses of human intravenous immunoglobulin (IVIG) ${ }^{1}$ and then subjected to the injection of a lethal dose of anti-Forssman antiserum. Human serum albumin for intravenous use and low pH maltose injections (controls for exogenous human protein and the IVIG vehicle, respectively) did not extend survival of control animals. IVIG-treated animals' sera contained normal levels of complement $\mathrm{C} 3$ and $\mathrm{C} 4$, and demonstrated normal capacity to activate these proteins. However, sera from IVIG-treated animals showed markedly impaired capacity to deposit $\mathrm{C} 3$ fragments on IgG-coated targets in vitro. These observations may have a bearing on the mechanism of IVIG action in ameliorating immune complex and complement dependent inflammatory lesions.

\section{Methods}

Animals. Female 200-350-g guinea pigs (NIH multipurpose) were obtained from colonies maintained by National Cancer Institute at Frederick, MD.

Reagents. Human serum immunoglobulin for intravenous use in $10 \%$ maltose, pH 4.25 (Gamimune), was purchased from Cutter Biologicals (Berkeley, CA). Human serum albumin 25\% solution for intravenous administration was also obtained from Cutter Biologicals.

1. Abbreviations used in this paper: E, guinea pig erythrocytes; EA, antibody-sensitized guinea pig erythrocytes; EAC1, antibody-sensitized guinea pig erythrocytes opsonized with purified complement component 1; EAC1,4, antibody-sensitized guinea pig erythrocytes opsonized with purified complement components 1 and 4; $\mathrm{GVB}^{2+}$, gelatin-containing isotonic Veronal-buffered saline supplemented with $0.15 \mathrm{mM} \mathrm{Ca}^{2+}$ and $1 \mathrm{mM} \mathrm{Mg}^{2+}$; ITP, idiopathic thrombocytopenic purpura; IVIG, high-dose intravenous immunoglobulin; SGVBS $^{2+}$, gelatin-containing Veronal-buffered isotonic sucrose supplemented with $0.15 \mathrm{mM} \mathrm{Ca}^{2+}$ and $1 \mathrm{mM} \mathrm{Mg}^{2+}$. 
Maltose hydrate grade I, guinea pig IgG, and guinea pig albumin were purchased from Sigma Chemical Co. (St. Louis, MO). Sodium [ $\left.{ }^{125} \mathrm{I}\right]-$ iodide was obtained from Amersham Corp. (Arlington Heights, IL). Iodobeads were purchased from Pierce Chemical Co. (Rockford, IL).

Buffers. Isotonic Veronal-buffered saline containing $0.1 \%$ gelatin, $0.15 \mathrm{mM} \mathrm{Ca}^{2+}$ and $1 \mathrm{mM} \mathrm{Mg}^{2+}\left(\mathrm{GVBS}^{2+}\right)$, isotonic Veronal-buffered saline containing $0.1 \%$ gelatin and $10 \mathrm{mM}$ EDTA buffer, and Veronal-buffered isotonic sucrose $(9.72 \% \mathrm{wt} / \mathrm{vol})$ containing $0.1 \%$ gelatin, $0.15 \mathrm{mM} \mathrm{Ca}^{2+}$ and $1 \mathrm{mM} \mathrm{Mg}^{2+}$ were prepared as previously described (7). A 60:40 mixture of this last buffer and $\mathrm{GVBS}^{2+}$ was used in some experiments $\left(\mathrm{SGVBS}^{2+}\right)$.

Complement components. Guinea pig first component of complement $(\mathrm{C} 1)$ was purchased from Cordis Laboratories (Miami, FL). Guinea pig C3 was purified by a modification of the procedure of Hammer et al. (8) designed for human C3. Human C4 was also purified by the method of Hammer et al. (8).

Anti-Forssman antiserum. Rabbit anti-Forssman antisera were prepared by previously described methods using boiled sheep erythrocyte stromata as the antigen source (9). Hemolytic antibody titration was performed by the method of Mayer (10). Two batches of antiserum with different titers were used. The lethal dose of the heat-inactivated anti-Forssman antiserum (minimum amount of serum required to kill $100 \%$ of normal guinea pigs weighing $350-500 \mathrm{~g}$ in $10 \mathrm{~min}$ or less) was determined from the results of the preliminary experiments and was found to be $1.15 \mu \mathrm{l} / \mathrm{g}$ of body weight for lower titer batch of antiserum, and $0.45 \mu \mathrm{l} / \mathrm{g}$ for the higher titer batch. However, both were uniformly lethal at the doses noted.

Antibodies. Rabbit polyclonal IgG anti-guinea pig C3 was purified from the sera of rabbits repeatedly immunized intravenously with purified guinea pig C3 in Freund's adjuvant. Rabbits repetitively immunized with whole, washed guinea pig erythrocytes served as the source of anti-erythrocyte antibody used for in vitro $\mathrm{C} 3$ binding studies. IgG fractionation of these sera included sequential ammonium sulfate precipitation, Sephacel G-200 sieving chromatography and DEAE anion exchange chromatography. FITC labeled affinity-purified goat immunoglobulins specific for rabbit IgG and guinea pig C3 was obtained from Kirkegaard \& Perry Laboratories, Inc. (Gaithersburg, MD).

Radiolabeling of antibodies. Radioiodination of rabbit IgG antiguinea pig $\mathrm{C} 3$ was accomplished using the lodobeads method. Briefly, $300 \mathrm{mg}$ of IgG was incubated with $1 \mathrm{mCi}$ of ${ }^{125} \mathrm{I}$ (Amersham Corp.), and three Iodobeads for $30 \mathrm{~min}$ with occasional agitation at room temperature. Free iodine was then separated from protein-bound isotope by passing the labeled material through a prepacked PD10 (Sephadex G-25M) column (Pharmacia Fine Chemicals, Piscataway, NJ) that had been preequilibrated in isotonic PBS, $\mathrm{pH}$ 7.4.

IVIG treatment-3-d protocol. Guinea pigs were anesthetized with Rompun (Xylazine; Mobay Corp., Shawnee, KS) followed by Vetalar (Ketamine $\mathrm{HCl}$; Parke-Davis Co., Morris Plains, NJ) and then infused via a hind limb vein with the desired doses of immunoglobulin, albumin or $10 \%$ maltose solution, $\mathrm{pH} 4.25$, for three consecutive days. On day $4,24 \mathrm{~h}$ after the last injection, Forssman shock was provoked.

IVIG treatment-one injection protocol. Guinea pigs were anesthetized as usual and then very slowly infused with a single dose of human IVIG or albumin equivalent to that given over the period of $3 \mathrm{~d}$. The human serum albumin was predialyzed such that both proteins were delivered in $10 \%$ maltose, $\mathrm{pH} 4.25 .3 \mathrm{~h}$ after the injection, when the animals had recovered from anesthesia, Forssman shock was elicited. Experiments using guinea pig IgG instead of human IVIG were carried out using the same protocol.

Forssman shock. Forssman shock was induced by injection of a predetermined lethal dose of rabbit anti-Forssman antiserum into the hind limb vein of guinea pigs. The symptoms seen in these animals were as follows: rubbing of the nose, labored breathing, sneezing, coughing, prostration, and death, usually evolving rapidly over 2 to 7 $\mathrm{min}$. Blood samples were taken by retroorbital sinus puncture before and after shock in order to measure C3, C4 titers and level of human IgG.
Preparation of lung samples for immunohistochemical studies. After death from Forssman shock, the rib cage was opened and multiple samples were taken from various lobes of the lung. Specimens were immediately embedded in Tissue-Tek medium (Ames Division, Miles Laboratories, Elkhart, IN) and frozen in dry ice with absolute methanol. Frozen specimen blocks were kept at $-20^{\circ} \mathrm{C}$ until use for immunochemical analysis.

Direct immunofluorescence for rabbit IgG and guinea pig $C 3$ in guinea pig lung tissue. Frozen blocks of guinea pig lung tissue were mounted in a Reichert Histostat microtome (AO Reichert Scientific Instruments, Buffalo, NY) and 6- $\mu \mathrm{m}$ sections were cut and adhered to glass slides precoated with $2 \%$ BSA solution. Slides were allowed to dry completely, dipped for $30 \mathrm{~s}$ in acetone at $-20^{\circ} \mathrm{C}$, and then washed in PBS for $5 \mathrm{~min}$ at room temperature. $250 \mu \mathrm{l}$ of FITC-labeled goat anti-rabbit $\operatorname{IgG}$ or goat anti-guinea pig $\mathrm{C} 3 \mathrm{IgG}$ diluted 1:50 was placed on corresponding slides to completely cover tissue sections and allowed to incubate for $20 \mathrm{~min}$ at room temperature. The slides were blotted dry and then placed in a beaker containing PBS $+0.5 \%$ BSA at room temperature for $5 \mathrm{~min}$. The wash was repeated twice more in fresh buffer, then excess fluid was blotted away, a drop of mounting fluid was put on the tissue sections, and a coverslip placed for fluorescence photomicroscopy.

Complement titrations. Hemolytic complement titrations of guinea pig $\mathrm{C} 4$ and $\mathrm{C} 3$ were performed using standard published procedures (7).

Levels of human IgG in guinea pig sera. Concentrations of human IgG in guinea pig sera were determined using radial immunodiffusion plates (AccraAssay; ICN Immunobiologicals, Lisle, IL) and known calibrating standards. These plates gave no significant reactivity with guinea pig sera alone.

In vitro $C 3$ binding studies. Two-tenths of $1 \mathrm{ml}$ of guinea pig erythrocytes at $2.7 \times 10^{8}$ cells $/ \mathrm{ml}$ were incubated with $0.1 \mathrm{ml}$ of diluted rabbit IgG anti-guinea pig erythrocyte antibody or $0.1 \mathrm{ml}$ of buffer for $30 \mathrm{~min}$ at $37^{\circ} \mathrm{C}$. A series of separate reaction tubes containing buffertreated unsensitized guinea pig erythrocytes (E) or antibody sensitized guinea pig erythrocytes (EA) were prepared and the cells were washed and pelleted. $400 \mu \mathrm{l}$ of undiluted normal guinea pig serum, sera from animals treated with graded doses of IVIG in one injection $(600,1,200$, and $1,800 \mathrm{mg} / \mathrm{kg}$ ), and serum from an animal treated with albumin/ maltose in volumes equivalent to IVIG at $1,800 \mathrm{mg} / \mathrm{kg}$, were each added to one pair of EA and $\mathrm{E}$ tubes. The tubes were placed in a water bath at $37^{\circ} \mathrm{C}$. At $0,2,5,15$, and $30 \mathrm{~min}$, duplicate $40-\mu \mathrm{l}$ samples were taken from each tube and transferred to wash tubes with ice-cold EDTA buffer. The intact erythrocytes in these samples were pelleted and the extent of lysis was determined by measuring free hemoglobin in the corresponding supernatants spectrophotometrically. The pellets were then washed again and resuspended in $200 \mu \mathrm{l}$ of GVBS${ }^{2+} .10 \mu \mathrm{l}$ of ${ }^{125}$ I-labeled rabbit IgG anti-guinea pig $\mathrm{C} 3$ was added to each tube and the mixture incubated for $60 \mathrm{~min}$ at $0^{\circ} \mathrm{C}$. After two further washes in ice-cold EDTA buffer, the pellets were counted in a gamma counter. Where appropriate, counts were corrected for the calculated percentage of hemolysis. Preliminary studies showed that results obtained by mathematically correcting for lysis closely paralleled those obtained using serum immunodepleted of $\mathrm{C} 8$ and thus incapable of hemolysis (11). In another series of experiments, guinea pig erythrocytes at 2.7 $\times 10^{8}$ cells $/ \mathrm{ml}$ were sensitized with rabbit IgG anti-guinea pig erythrocyte antibody diluted in $\mathrm{SGVBS}^{2+}$; one portion of these cells was incubated with partially purified guinea pig $\mathrm{Cl}$ component $(5,000$ hemolytic $\mathrm{U} / \mathrm{ml}$ ) for $15 \mathrm{~min}$ at $30^{\circ} \mathrm{C}$ and washed twice in $\mathrm{SGVBS}^{2+}$ (EAC1). One aliquot of $\mathrm{EACl}$ was then further treated with purified human $\mathrm{C4}$ $(5,000$ hemolytic $\mathrm{U} / \mathrm{ml})$ for $45 \mathrm{~min}$ at $37^{\circ} \mathrm{C}(\mathrm{EACl}, 4) .100-\mu \mathrm{l}$ aliquots of EA, EACl, and EAC1,4 were pelleted and then resuspended in 200 $\mu \mathrm{l}$ of normal guinea pig serum, heat-inactivated guinea pig serum, and serum from a guinea pig treated with IVIG, $1,800 \mathrm{mg} / \mathrm{kg}$. The tubes were placed in a $37^{\circ} \mathrm{C}$ water bath, duplicate $40-\mu \mathrm{l}$ samples were taken at 5- and 30-min time points and transferred to wash tubes with icecold EDTA buffer. C3 uptake was quantified with radiolabeled anti-C3 as described above and counts were corrected for lysis. 


\section{Results}

Effect of IVIG on survival in Forssman shock. The initial experimental group of animals $(n=10)$ was treated for three consecutive days with infusion of human $\mathrm{IgG}$ at $600 \mathrm{mg} / \mathrm{kg}$ i.v., a protocol yielding a final total dose similar to that employed in human ITP (12). Two control groups were treated in parallel. The first group $(n=8)$ received $10 \%$ maltose in water, $\mathrm{pH} 4.25$, at volumes equivalent to those delivered to the experimental group, while the second control group $(n=7)$ was infused for $3 \mathrm{~d}$ with $25 \%$ human albumin for intravenous use at $600 \mathrm{mg} / \mathrm{kg}$. Forssman shock was provoked on the fourth day by injection of anti-Forssman anti-serum at $1.15 \mu \mathrm{l} / \mathrm{g}$. As shown in Fig. 1, survival time was significantly increased in guinea pigs treated with IVIG. Among this group two animals (20\%) survived, and the median survival time was three to fivefold prolonged relative to control animals. No animal treated with albumin or maltose survived the injection of the lethal dose of anti-Forssman antibody. Survival of these control group animals was actually marginally shorter than that of entirely untreated animals, but this difference was not statistically significant. When differences in survival curves among the three groups were compared by the Kruskal-Wallis test, a $\chi^{2}$ value of 6.41 was obtained $(P<0.05)$. Comparison of the maltose and albumin groups revealed near-identity $\left(c^{2}=0.04\right)$, leaving a residual $\chi^{2}$ of 6.37 attributable to the difference between the two control groups and the IVIG group $(P<0.02)$. To avoid the repetitive anesthesia and multiple handling of animals required by the 3-d treatment protocol, in the next series of experiments animals $(n=8)$ were infused with a dose of IVIG equivalent to that administered over the period of $3 \mathrm{~d}$ $(1,800 \mathrm{mg} / \mathrm{kg})$ in one slow injection. Controls $(n=7)$ were treated with the same volume of $10 \%$ maltose $\mathrm{pH} 4.25$ supplemented with human albumin to $1,800 \mathrm{mg} / \mathrm{kg}$. After recovery from anesthesia (usually $3 \mathrm{~h}$ later), animals were subjected to

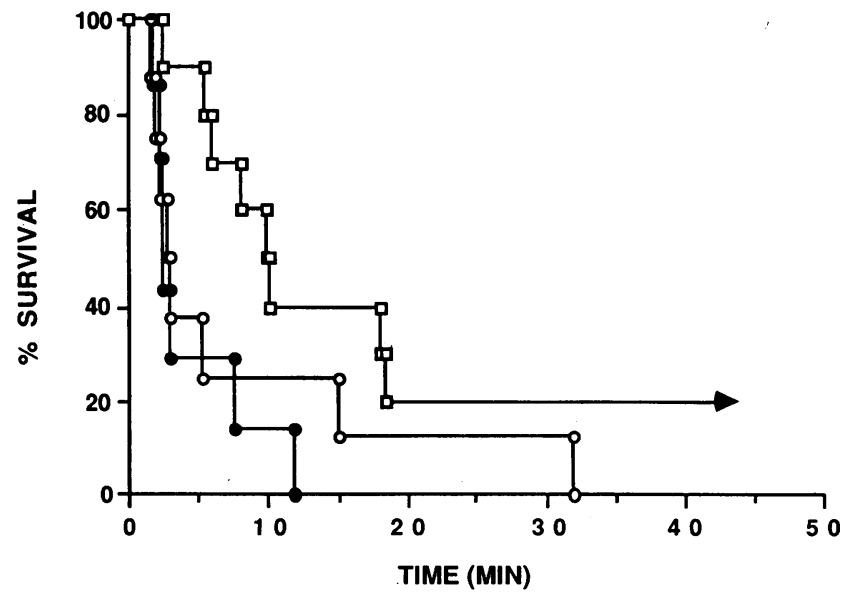

Figure 1. The effect of IVIG infusions on survival in Forssman shock. Guinea pigs $(n=10)$ were treated with $600 \mathrm{mg} / \mathrm{kg}$ of IVIG (一 -) for three consecutive days, while two control groups received the same dose of albumin $(n=7,-\bullet-)$ or the same volume of low pH maltose solution $(n=8,-\circ-)$. The survival curves of two control groups were almost identical $\left(\chi^{2}=0.04\right)$, while the difference between the two control groups and the IVIG group was highly significant $\left(\chi^{2}=6.37, P<0.02\right)$. No control animal survived, while among IVIG-treated animals there were two survivors (represented by the arrow in survival graph).

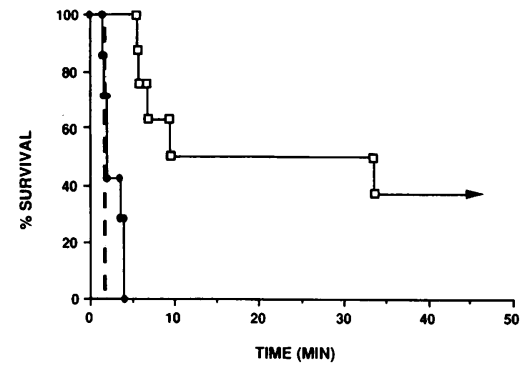

Figure 2. The effect of IVIG on survival in Forssman shock after one dose infusion. Eight guinea pigs were anesthetized and injected slowly with IVIG at $1,800 \mathrm{mg} / \mathrm{kg}($ (-ロ $)$ Controls $(n=7$, $-\bullet-)$ received $10 \%$ maltose, $\mathrm{pH} 4.25$ sup-

plemented with human albumin for intravenous use to yield 1,800 $\mathrm{mg} / \mathrm{kg} .38 \%$ of guinea pigs treated with IVIG survived Forssman shock (arrow) and median survival for the entire group was fivefold longer than controls or completely untreated animals. The difference in survival was highly significant as evaluated by the Wilcoxon test $(P<0.001)$. The vertical dashed line represents the median survival of five completely untreated guinea pigs injected with anti-Forssman antiserum. These did not differ from albumin/maltose controls.

Forssman shock by injection of a lethal dose of anti-Forssman antiserum. A more potent anti-Forssman anti-serum was used in this series; median survival time of entirely untreated animals was 2 min. Pretreatment with IVIG prevented death in $38 \%$ of animals and markedly increased the duration of survival in those IVIG treated animals that did succumb (Fig. 2). All control animals died within $4 \mathrm{~min}$ after the injection of anti-Forssman antiserum. The differences in survival of the two groups were highly significant when analyzed by the Wilcoxon test $(P<0.001)$.

To examine the possibility that the IVIG effect resulted from the heterologous source of IVIG, lyophilized guinea pig IgG and albumin were reconstituted with distilled water; maltose was added to make $10 \%$ solutions and the $\mathrm{pH}$ of each was brought to 4.25 with $1 \mathrm{~N} \mathrm{HCl}$. Six guinea pigs were anesthetized; four animals were slowly infused with guinea pig $\mathrm{IgG}$ at $1,800 \mathrm{mg} / \mathrm{kg}$; two received guinea pig albumin at the same dose. $3 \mathrm{~h}$ after these infusions all animals were injected with $0.4 \mu \mathrm{l} / \mathrm{g}$ of anti-Forssman antibody. Animals treated with guinea pig albumin died within $2 \mathrm{~min}$, whereas among guinea pig IgG-treated animals two survived and the two that eventually succumbed to Forssman shock lived for 15 and $20 \mathrm{~min}$, respectively, after provocation.

Dose-response of survival and levels of human IgG in guinea pig sera. Three groups of animals ( $n=4$ in each group) were treated with increasing doses of IVIG $(600,1,200$, and $1,800 \mathrm{mg} / \mathrm{kg}$ ) using the one-injection protocol. Control animals $(n=9)$ were infused with the same volume of maltose solution as required for $1,800 \mathrm{mg} / \mathrm{kg}$ of IVIG, containing instead $1,800 \mathrm{mg} / \mathrm{kg}$ of human albumin. $3 \mathrm{~h}$ later, Forssman shock was provoked. A stepwise enhancement of survival was seen in the groups receiving 1,200 and $1,800 \mathrm{mg} / \mathrm{kg}$, whereas the $600-\mathrm{mg} / \mathrm{kg}$ group was not markedly different from controls (Fig. $3 a$ ). When survival time was studied as a function of the concentration of human IgG obtained in the animals' sera, a strong positive correlation was found between these parameters by the Spearman rank correlation method (Spearman's rho $=0.92, P<0.001$, see Fig. $3 b$ ). To exclude the possibility that this correlation arose from accumulated group to group variation (based, for example, on volume of infusions), we examined the relationship of survival to IgG level within each treatment subgroup. While the small numbers precluded sta- 

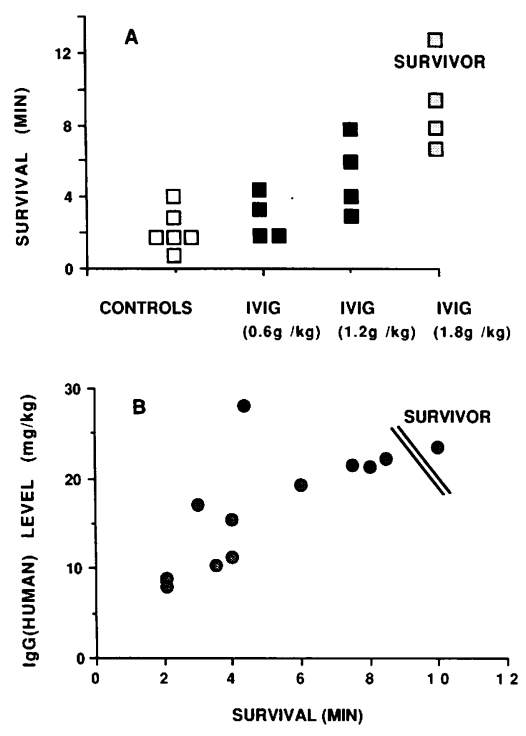

Figure 3. (A) Correlation of survival with human IgG dosage levels in guinea pigs. Three groups of four guinea pigs were given graded doses of IVIG: $600 \mathrm{mg} / \mathrm{kg}$ (๘), 1,200 $\mathrm{mg} / \mathrm{kg}(\mathbf{\square})$, and 1,800 $\mathrm{mg} / \mathrm{kg}(\square)$. Controls ( $\square$ ) received $1,800 \mathrm{mg} / \mathrm{kg}$ of albumin in $10 \%$ maltose, $\mathrm{pH}$ 4.25. An apparent dose-dependent increase in duration of survival was observed. $(B)$ Survival duration was plotted against the concentration of human IgG obtained in sera of guinea pigs in the above three treat-

ment subgroups. A highly significant correlation was found between the two parameters by the Spearman's rank correlation method (Spearman's rho $0.92 P<0.001$ ). Entries $(\bullet)$ are individual animals. Survival duration also correlated positively with human IgG level within each subgroup (rho 0.80-0.95).

tistical significance, a very strong positive correlation was seen within each subgroup (Spearman's rho 0.80-0.95), suggesting that the relation of survival to IgG level was homogenous and that pooling of the groups for statistical purpose was justifiable.

Titers of $C 3$ and $C 4$ before and after provocation of Forssman shock. In our initial studies, blood samples for $\mathrm{C} 3$ and $\mathrm{C} 4$ titers were taken before treatment, before Forssman shock and at various time points after shock to assess whether IVIG altered overall complement consumption. Infusions of IVIG, maltose, and/or albumin had no effect on $\mathrm{C} 3$ and $\mathrm{C} 4$ titers, since pretreatment and preshock values remained totally unchanged (data not shown). This finding confirmed our previous observations with IVIG in a guinea pig model (11). After the injection of anti-Forssman antiserum, the average percentage of $\mathrm{C} 3$ and $\mathrm{C} 4$ consumed was not significantly different between the various controls and IVIG treated group of animals when assessed by the $f$-test (Table I). To assess the possibility of a difference in the kinetics of complement consumption after the injection of anti-Forssman antiserum, regularly timed blood samples were collected (before shock and 1, 2, 4, 8 , and $60 \mathrm{~min}$ after shock) for $\mathrm{C} 3$ and $\mathrm{C} 4$ titers in one group of maltose/albumin-treated animals and one group of guinea pigs

Table I. The Effect of IVIG on C3 and C4 Consumption during Forssman Shock

\begin{tabular}{llc}
\hline & \multicolumn{2}{c}{ Average \% consumed } \\
\cline { 2 - 3 } Pretreatment & $\mathrm{C} 4$ & $\mathrm{C} 3$ \\
\hline Maltose $(n=8)$ & $35.8 \pm 5.1$ & $27.5 \pm 3.5$ \\
Albumin $(n=8)$ & $20.3 \pm 4.7$ & $22.9 \pm 4.2$ \\
IVIG $(n=10)$ & $32.2 \pm 4.5$ & $25.4 \pm 3.4$ \\
\hline
\end{tabular}

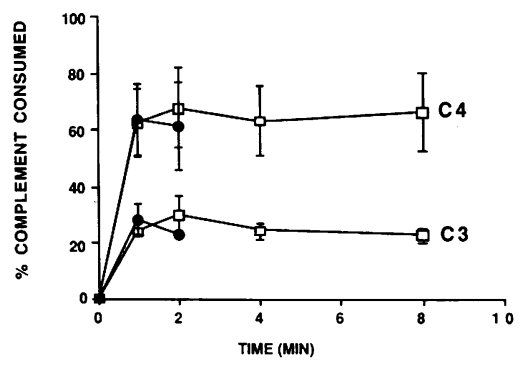

Figure 4. Time-course of complement consumption in IVIGtreated animals and in the control animals. Blood samples were collected from IVIG (ㅁ) and albumin/maltose treated $(\bullet)$ groups of guinea pigs before and at $1,2,4$, and $8 \mathrm{~min}$ after provocation of Forssman shock for determination of complement $\mathrm{C} 3$ and $\mathrm{C} 4$ levels. The consumption of $\mathrm{C} 3$ and $\mathrm{C} 4$ reached the maximum in $1 \mathrm{~min}$ and did not change markedly thereafter in both IVIG animals and controls. All controls died before 4-min specimens could be obtained. However, complement consumption at 2 min was essentially the same as that noted at the time of death in all other animals treated with this batch of antiserum. The extent of C3 and C4 consumption was not different between the two groups. Data shown here represent means of three animals; bars represent standard errors. Where error bars are not shown, they fall inside the symbol.

injected with $1,800 \mathrm{mg} / \mathrm{kg}$ of IVIG $3 \mathrm{~h}$ before shock. As shown in Fig. 4, plasma C3 and C4 titers fell precipitously in IVIGtreated animals $1 \mathrm{~min}$ after injection of anti-Forssman antiserum and remained essentially unchanging for at least $7 \mathrm{~min}$ thereafter. $\mathrm{C} 4$ and $\mathrm{C} 3$ were consumed to an identical extent in control animals at $1 \mathrm{~min}$, then plateaued at $2 \mathrm{~min}$, again at levels not distinguishable from IVIG-treated animals. Despite the apparent lack of progressive complement consumption after $1 \mathrm{~min}$, all controls died before $4 \mathrm{~min}$. Their overall extent of complement $\mathrm{C} 3$ and $\mathrm{C} 4$ consumption at 2 min was not different from that observed at death in all other animals, treated on the same protocol and receiving the same antiForssman preparation $(30.1 \pm 6.6 \%$ for $\mathrm{C} 3$, and $61.6 \pm 15.6$ for C4). In IVIG-treated long-term survivors, some further consumption of complement was noted at the $60-$ min point. Thus, these survivors actually sustained greater total complement consumption than their control counterparts.

Immunohistochemistry. Lung tissue specimens taken postmortem from animals treated with IVIG and maltose/albumin were immediately frozen and cut into $6-\mu \mathrm{m}$ thick slides. Tissue slides were incubated with FITC-labeled goat anti-rabbit IgG. It is evident from Fig. 5, $A$ and $B$ that anti-Forssman IgG antibody was deposited in the pulmonary parenchyma, presumably on endothelial and connective-adventitial cells, in both IVIG-infused animals and controls. Normal guinea pig lung tissues or tissues stained with FITC-labeled goat antimouse IgG showed no fluorescence. Lung tissue from animals infused with IVIG and not subjected to Forssman shock and tissue from animals receiving nonimmune rabbit serum were likewise negative (Fig. $5 C$ ). Thus, IVIG did not appear to act by blocking anti-Forssman IgG uptake in the lung. Evaluation of sections stained with anti-C3 was more difficult. All control tissues, including totally normal lung, showed significant background staining. While tissues from animals dying of Forssman shock showed distinctly stronger staining, it was not possible to ascertain whether IVIG treatment altered C3 deposition. To address the effect of IVIG on C3 fragment deposition more quantitatively, we next developed an in vitro model.

Inhibition of C3 uptake onto IgG coated GPE by IVIG in vitro. As a means of addressing the potential mechanism of the IVIG effect in an in vitro model, guinea pig erythrocytes sen- 

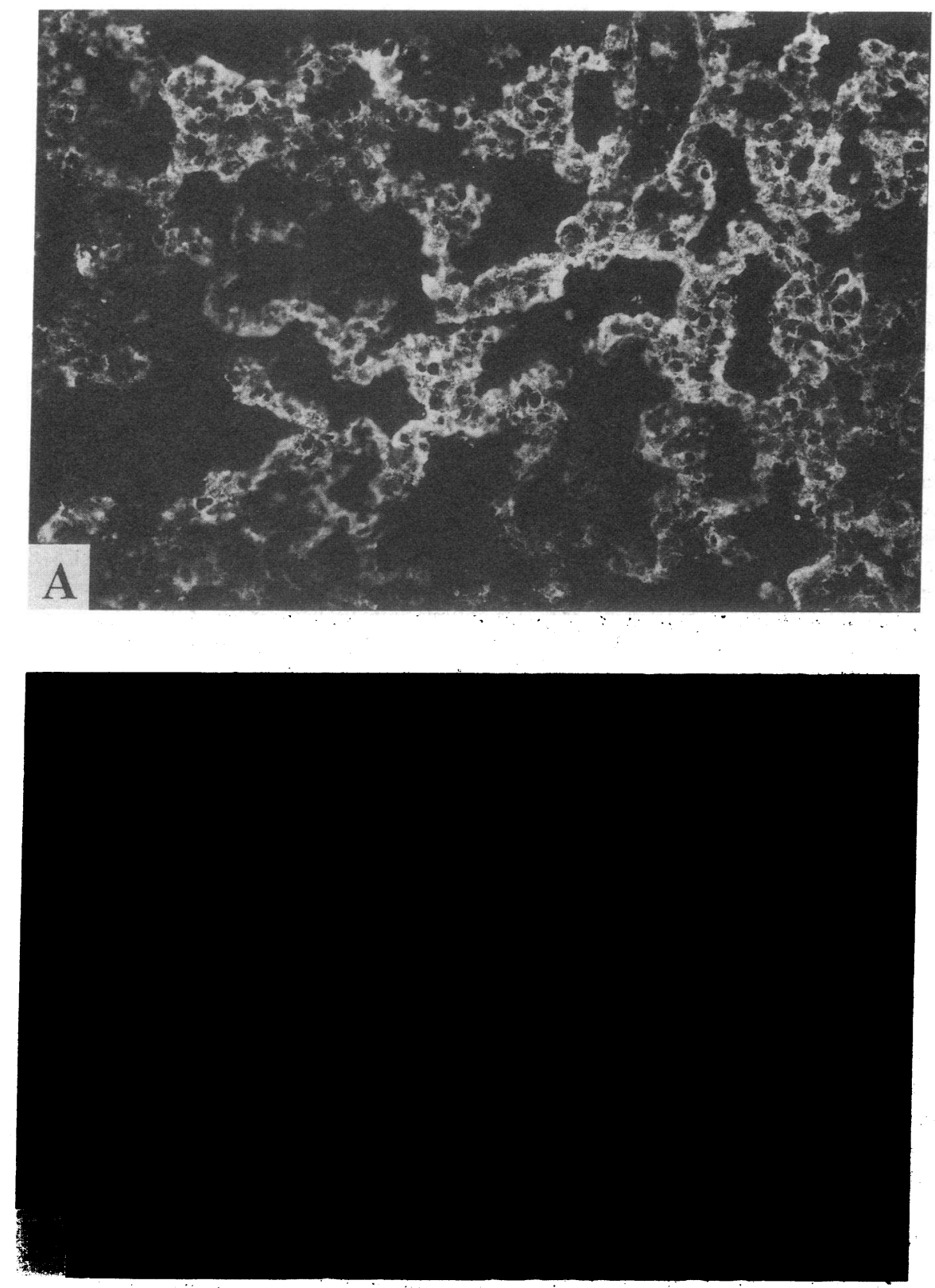

Figure 5. (A) Lung tissue section from an IVIG treated animal after Forssman

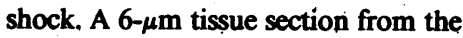
lung of an animal treated with IVIG at $1,800 \mathrm{mg} / \mathrm{kg}$ and then subjected to Forssman shock, was incubated with FITC-labeled goat anti-rabbit IgG.

Note the intense fluorescence of parenchyma. (B) Lung tissue specimen from an albumin/maltose treated animal after Forssman shock. Lung tissue was taken from an animal treated with albumin/maltose immediately after its death from Forssman shock. The 6- $\mu \mathrm{m}$ specimen was incubated with FITC-labeled goat anti-rabbit IgG. Lung parenchyma showed positive reaction (intense fluorescence). (C) Lung tissue section from an animal treated with nonimmune rabbit serum. A guinea pig was injected with a volume of heated and sheep erythrocyte preadsorbed nonimmune rabbit serum equivalent to the lethal dose of antiForssman antiserum; 10 min after the injection the animal was killed and lung samples immediately taken and frozen. $6-\mu \mathrm{m}$ sections were incubated with FITC-labeled goat anti-rabbit IgG. No fluorescence of lung tissue was observed despite extended exposure times (accounting for the brighter overall image). 

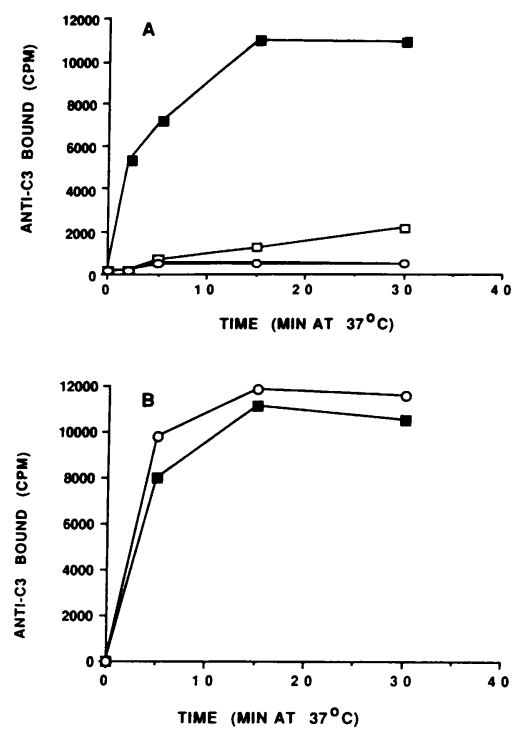

Figure 6. $(A)$ The effect of IVIG on C3 uptake by IgG sensitized guinea pig E. Guinea pig $E$ were sensitized with anti-guinea pig erythrocyte IgG antibodies and then incubated with normal guinea pig serum (一- -), and sera from animals treated with IVIG at $600 \mathrm{mg} / \mathrm{kg}$ (一 一), 1,200 mg/kg (一O-) and 1,800 $\mathrm{mg} / \mathrm{kg}(-\bullet-)$. C3 uptake was quantified by subsequent binding of ${ }^{125}$ I labeled anti-guinea pig C3, and was essentially eliminated by IVIG. (B) IgG sensitized guinea pig $E$ were and incubated with normal guinea pig serum (- -) and serum from an animal treated with human albumin (一 - -) at $1,800 \mathrm{mg} / \mathrm{kg}$ in $10 \%$ maltose $\mathrm{pH} 4.25$. C3 uptake was determined by subsequent binding of ${ }^{125} \mathrm{I}$ labeled anti-guinea pig $\mathrm{C} 3$. Albumin pretreatment had no impact on C 3 uptake.

sitized with rabbit anti-guinea pig erythrocyte antibody were incubated with undiluted normal guinea pig serum, serum obtained from animals treated with increasing doses of IVIG and serum from an animal injected with albumin in maltose. At various time points, aliquots were removed to quantitate $\mathrm{C} 3$ binding by uptake of ${ }^{125} \mathrm{I}$ anti-guinea pig $\mathrm{C} 3$ onto the sensitized erythrocytes. At all time points IVIG almost completely suppressed the uptake of $\mathrm{C} 3$ (Fig. $6 \mathrm{~A}$ ). Albumin/maltose treatment had no effect whatever on $\mathrm{C} 3$ uptake relative to the normal guinea pig serum (Fig. $6 \mathrm{~B}$ ). The same phenomenon was observed in another in vitro experiment in which IgGsensitized erythrocytes were sensitized stepwise with purified $\mathrm{C} 1$ and $\mathrm{C} 4$ complement components and then incubated with normal guinea pig serum, heat inactiveated guinea pig serum and serum from an animal treated with $1,800 \mathrm{mg} / \mathrm{kg}$ of IVIG.

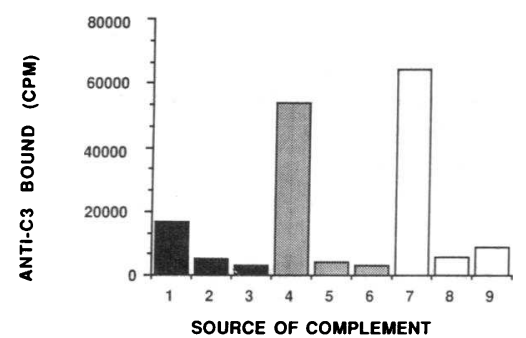

Figure 7. The effect of IVIG on C3 uptake by guinea pig EA (IgG) sensitized with purified $\mathrm{C} 1$ and $\mathrm{C} 4$ complement components. IgG sensitized guinea pig erythrocytes $(\boldsymbol{\varpi})$, EA treated with purified $\mathrm{Cl}(\boldsymbol{\square})$ or $\mathrm{Cl}$ followed by $\mathrm{C} 4$ ( $\square$ )

were incubated at $37^{\circ} \mathrm{C}$ with normal guinea pig serum $(1,4,7)$, heatinactivated guinea pig serum $(2,5,8)$ and serum from an animal pretreated with IVIG at $1,800 \mathrm{mg} / \mathrm{kg}(3,6,9)$. Duplicate samples were taken at 5-min and 30-min time points. $\mathrm{C} 3$ uptake was monitored by binding of radiolabeled anti-C3. The uptake of $\mathrm{C} 3$ was inhibited at both 5- (shown here) and 30-min (not shown) time points to virtually background levels by the serum from an IVIG-treated animal. The effect was maintained or enhanced by preloading the cells with $\mathrm{Cl}$ and $\mathrm{C4}$, suggesting that the action of IVIG occurred primarily at the $\mathrm{C} 3$ convertase or $\mathrm{C} 3$ binding step(s).
In all instances the $\mathrm{C} 3$ uptake, as measured by binding of radiolabeled anti-C3 antibody at 5- and 30-min time points, was inhibited to almost background levels (Fig. 7). That preloading the target cells with $\mathrm{C} 1$ and/or $\mathrm{C} 4 \mathrm{~b}$ residues did not reduce (and indeed enhanced) the IVIG effect suggested that the primary influence of IVIG was not at either of these potential interference points.

\section{Discussion}

Intravenous immunoglobulin has been shown to be effective in treating idiopathic thrombocytopenic purpura and a variety of other antibody-mediated autoimmune diseases. The mechanism of action is unclear, but it has been suggested that IVIG inhibits the binding of IgG-coated targets to phagocytic cells expressing IgG Fc receptors. We have explored the effect of IVIG on complement activation and on target tissue deposition. In a previous study (11), we found that IVIG suppressed complement-dependent clearance of particulate immune complexes in an in vivo system free of IgG-Fc receptor interactions. Our results suggested that IVIG may interfere with complement $\mathrm{C} 3$ fragment deposition onto IgM-sensitized erythrocytes, and that this could be an important mechanism of action of IVIG in immune cytopenias. We speculated that IVIG might be a more effective complement activation modulator in an IgG-dependent model, especially in view of the higher densities of target-bound IgG required, relative to IgM, to initiate efficient complement activation (13). To examine this possibility, we chose Forssman shock, an in vivo model of tissue damage, which is complement dependent and IgG mediated. In spite of the long history of research on Forssman shock, the exact mechanisms involved are still not known. There is a general agreement among investigators that antiForssman antibodies of IgG class react with antigenic determinants on pulmonary endothelial cells, triggering the complement cascade and ultimately leading to endothelial cell damage in Forssman shock. In this respect it is similar to the postulated pathophysiologic mechanism of Kawasaki disease (14), the vasculitic pathology which is responsive to IVIG therapy (15). The requirement for an intact classical pathway of complement activation is absolute, and there is no convincing evidence that cellular $\mathrm{Fc}$ receptors participate in any way in the pathogenesis of the lesion.

In the present study, infusions of high doses of IVIG significantly increased survival time and/or prevented death in guinea pigs subjected to Forssman shock. No control animal (treated with albumin and/or maltose) survived injections of lethal doses of anti-Forssman antibodies. In addition, experiments in which animals were treated with high doses of guinea pig IgG and albumin proved that the same protective phenomenon was operative in a homologous system. The effect of IVIG on survival in Forssman shock was significant when the immunoglobulin was administered over $3 \mathrm{~d}$, but was even more striking when the dose of IVIG was administered in one slow injection and Forssman shock elicited a few hours later. This finding is most probably due to the higher plasma levels of human IgG obtained by this latter protocol. Presumably, the majority of the infused IgG remained within the intravascular space after a one-dose infusion, while over the longer period of the 3-d protocol it distributed to both the extra and intravascular space, with resultant lower plasma levels (mean 
human IgG level $=8.7 \mathrm{mg} / \mathrm{ml}$ ). The effectiveness of the one dose protocol and the dependance of effect on IVIG plasma levels was further supported by the results of the experiment in which graded doses of IVIG were given by the single dose protocol. We found a strong positive correlation between the survival time and concentration of human IgG obtained in animals' sera. This result was confirmed within each subgroup, suggesting that the correlation was not an artifact of group-togroup variation in the pooled data.

We considered several possible mechanisms of IVIG effect in Forssman shock. No decrease in serum complement titers was found in IVIG-treated animals before shock. Thus, protective decomplementation before shock was not responsible for the effect noted. Interference with the binding of antiForssman antibodies to target cells in the pulmonary vascular bed or parenchyma was also deemed unlikely based on the results of our immunohistochemical study. In both control animals and animals treated with IVIG, FITC-labeled goat anti-rabbit IgG reacted strongly with pulmonary parenchymal endothelial and adventitial cells. Multiple control experiments were performed to rule out various unexpected competitive antigen-antibody interactions. These included adsorption of human IVIG with sheep erythrocytes to remove any competitive anti-Forssman antibodies, premixing of anti-Forssman antisera with IVIG, and adsorption of anti-Forssman antisera with insolubilized guinea pig serum proteins. None of these maneuvers altered the expected effectiveness of the IVIG or the lethality of the anti-Forssman antibodies. Blockade of complement activation per se also plays no role in IVIG effect in Forssman shock, since the percentage of $\mathrm{C} 3$ and $\mathrm{C} 4$ consumed at various time points following provocation of shock was not different in IVIG treated animals compared to animals treated with albumin and maltose. In fact, in IVIGtreated long-term survivors these complements continued to be gradually consumed at later time points. The cytotoxic effects of complement activation hinge on the deposition of early activation products, notably $\mathrm{C} 4 \mathrm{~b}$ and $\mathrm{C} 3 \mathrm{~b}$, onto target surfaces. These target-bound residues serve as an obligate nidus for the assembly of the membrane attack complex and also may localize the production of such complement-derived mediators as the anaphylatoxins (16). We and others have shown that IgG is a very efficient acceptor of C4 and C3 fragments (17-20), both as a component of immune complexes and an innocent bystander. Indeed, some evidence suggests a noncovalent interaction between free IgG and unactivated C3 which may favor C3b-IgG complex formation on activation (21). Thus, supraphysiologic amounts of ambient IgG might divert $\mathrm{C} 4 \mathrm{~b}$ and/or $\mathrm{C} 3 \mathrm{~b}$ from target membranes and suppress localized complement-mediated pathology. We thus examined the capacity of guinea pig sera containing high concentrations of human IVIG to deposit C3 fragments on a model target in vitro (guinea pig erythrocytes bearing IgG rabbit anti-GPE antibodies). Our data suggest gross suppression of $\mathrm{C} 3$ fragment uptake in IVIG-bearing sera which is not found in the sera of animals treated with either maltose vehicle solution or human albumin. Interference with the $\mathrm{C} 1$ or $\mathrm{C} 4$ steps of the complement cascade, two potential interaction points for IVIG, does not seeem to be operative, since preloading the target cells with $\mathrm{Cl}$ or $\mathrm{Cl}$ and $\mathrm{C} 4$ did not diminish the eventual influence of IVIG on $\mathrm{C} 3$ binding. These findings are parallel to, but much more marked than, our previous findings with IgM-coated targets (11), and also are congruent with the earlier studies of
Berger et al. carried out in dilute sera (22). Additional support was obtained using a solid-phase assay system. Microplate wells were coated with immune complexes prepared from human albumin and rabbit anti-human albumin IgG. Exposure of these wells to normal human serum supplemented with IVIG to $20 \mathrm{mg} / \mathrm{ml}$, resulted in $60 \%$ inhibition of $\mathrm{C} 3$ binding (as measured by uptake of radiolabeled anti-human $\mathrm{C} 3$ ) in the presence of IVIG. Taken together with the vigorous consumption of C4 and C3 noted in IVIG-treated animals submitted to Forssman shock, these data suggest that the presence of high levels of IVIG may indeed divert complement activation products from target surfaces without blocking activation per se.

Further studies are necessary to completely elucidate the mechanism of IVIG action in prolonged survival in Forssman shock. These will include assessment of the formation of human IgG-guinea pig C3b complexes after the injection of anti-Forssman antibodies and studies of cytotoxicity and complement fragment uptake in an in vitro system using cultured endothelial cells as targets for anti-Forssman antibodies. Nonetheless, the data presented here indicate that IVIG in very large doses may represent a useful therapeutic agent to modify acute complement-dependent tissue damage. IVIG is a natural product with remarkably little toxicity. Our findings provide a novel potential theoretical basis for the reports of rapid improvements in active vasculitic syndromes such as Kawasaki disease (15), or antibody and complement-dependent skin disease such as bullous pemphigoid after IVIG (23) and suggest that administration of IVIG in even higher doses than currently used be formally evaluated.

\section{References}

1. Coombs, R. R. A., and P. G. H. Gell. 1975. Classification of allergic reactions responsible for clinical hypersensitivity and disease. In Clinical Aspects of Immunology. P. G. H. Gell, R. R. A. Coombs, and P. J. Lachman, editors. Blackwell Scientific, London, England.

2. Tanaka, N., and E. H. Leduc. 1956. A study of the cellular distribution of Forssman antigen in various species. J. Immunol. 77:198-212.

3. Bauman, N., and W. Elliot. 1972. The relative efficacies of $7 \mathrm{~S}$ and 19S Forssman antibody in producing lesions in the guinea pig. Proc. Soc. Exp. Biol. Med. 139:670-672.

4. May, J. E., and M. M. Frank. 1972. Complement mediated tissue damage: Contribution of the classical and alternate complement pathways in the Forssman reaction. J. Immunol. 108:1517-1525.

5. Tsai, C. C., N. S. Taichman, W. H. Pulver, and E. Shonbaum. 1973. Heterophyle antibodies and tissue injury. III. A role for platelet in the development of lethal vascular injury during Forssman shock in guinea pigs. Am. J. Pathol. 72:179-199.

6. Nagai, H., Y. Kurimoto, and A. Koda. 1980. Immunopharmacological approach to Forssman shock. Microb. Immunol. 24:649655.

7. Gaither, T. A., M. M. Frank. 1979. Complement. In Clinical Diagnosis and Management by Laboratory Methods. J. B. Henry, editor. W.B. Saunders, Philadelphia. 1253.

8. Hammer, C. H., G. H. Wirtz, L. Renfer, H. D. Gresham, and B. F. J. Tack. 1981. Large scale isolation of functionally active components of the human complement system. J. Biol. Chem. 265:39954006.

9. Mayer, M. M. 1961. In Experimental Immunochemistry. E. A. Kabat, and M. M. Mayer, editors. 2nd Ed. 150. Charles C. Thomas, Springfield, IL.

10. Mayer, M. M. 1961. In Experimental Immunochemistry. E. A. Kabat, and M. M. Mayer, editors. 2nd ed. Charles C. Thomas, Springfield, IL. 152-154. 
11. Basta, M., P. F. Langlois, M. Marques, M. M. Frank, and L. F. Fries. 1989. High-dose intravenous immunoglobulin modifies complement-mediated in vivo clearance. Blood. 74:326-333.

12. Imbach, P., S. Barandun, V. d'Apuzzo, A. Hirt, E. Rossi, M. Vest, C. Baumgartner, A. Morel, and H. P. Morel. 1981. High-dose intravenous gammaglobulin for idiopathic thrombocytopenic purpura in childhood. Lancet i:1228-1230.

13. Humphrey, J. H., and R. R. Dourmashkin. 1965. Electron microscope studies of immune cell hemolysis. In Complement Ciba Foundation Symposium. Little Brown \& Co., Boston, MA. 175-179.

14. Leung, D. Y. M., T. Collins, L. A. Lapierre, R. S. Gelia, J. S. Pober. 1986. Immunoglobulin $M$ antibodies present in the acute phase of Kawasaki syndrome lyse cultured endothelial cells stimulated by gamma interferon. J. Clin. Invest. 77:1428-1435.

15. Newburger, J. W., M. Takahashi, and J. Burns. 1986. The treatment of Kawasaki syndrome with intravenous gamma globulin. N. Engl. J. Med. 315:341-347.

16. Fries, L. F., and M. M. Frank. 1987. Molecular mechanisms of complement action. In The Molecular Basis of Blood Diseases. G. Stamatoyannopoulos, A. W. Ninhuis, P. Leder, and P. W. Majerus. editors. W.B. Saunders, Philadelphia. 465-470.
17. Gadd, K. J., and K. B. M. Reid. 1981. The binding of complement component $\mathrm{C} 3$ to antibody-antigen aggregates after activation of the alternative pathway in human serum. Biochem. J. 195:471-480.

18. Brown, E. J. M. Berger, K. A. Joiner, and M. M. Frank. 1983. Classical complement pathway activation by antipneumoccocal antibodies leads to covalent binding of $\mathrm{C} 3 \mathrm{~b}$ to antibody molecules. Infect. Immun. 42:594-598.

19. Fries, L. F., T. A. Gaither, C. H. Hammer, and M. M. Frank. 1984. C3b covalently bound to IgG demonstrates a reduced rate of inactivation by factors $\mathrm{H}$ and I. J. Exp. Med. 160:1640-1655.

20. Jacobs, R. J., M. Reichlin. 1983. C3-bearing immunoglobulin in human serum. J. Immunol. 130:2775-2781.

21. Kulics, J., E. Rajnavolgyl, G. Fust, and J. Gergely. 1983. Interaction of $\mathrm{C} 3$ and $\mathrm{C} 3 \mathrm{~b}$ with immunoglobulin G. Mol. Immunol. 20:805-810.

22. Berger, M., P. Rosenkranz, and C. Y. Brown. 1985. Intravenous and standard immune serum globulin preparations interfere with uptake of ${ }^{125} \mathrm{I}-\mathrm{C} 3$ onto sensitized erythrocytes and inhibit hemolytic complement activity. Clin. Immun. Immunopathol. 34:227-236.

23. Stiehm, E. R., E. Ashida, K. S. Kim, D. J. Winston, A. Haas, and R. P. Gale. 1987. Intravenous immunoglobulins as therapeutic agents. Ann. Intern. Med. 107:367-382. 